\title{
NANOFLUID ASSISTANCE IN MACHINING PROCESSES - PROPERTIES, MECHANISMS AND APPLICATIONS: A REVIEW
}

\begin{abstract}
A special group of hybrid assisted processes termed media-assisted processes which apply liquid media with special additives in the form of nanoparticles supplied to the cutting zone is overviewed. Special attention is paid to minimum quantity lubrication (MQL) technique with the use of nanofluids. In this review paper some important thermal and tribological effects resulting from the applications of various nanoparticles are outlined and compared. The MQL-nano cutting fluid mechanisms (rolling and ploughing) are described. In particular, some important quantitative effects concerning thermal and tribological behaviour of the cutting process as well as surface quality are presented.
\end{abstract}

\section{INTRODUCTION}

Media - assisted machining processes are classified as the third very important group of secondary assisting machining processes [1,2]. This group of hybrid processes incorporates high pressure and cryogenic cooling/lubrication applied by dedicated jets or cooling nozzle systems. In general, it addresses the problem of supporting the cutting process by introducing additional liquid and /or gaseous media into the cutting zone. The research on the use of nanofluids for MQL applications has gained more attention for over the past two decades. However, a lot of individual nanoparticles can be added as an additive to coolants (cutting fluids) / lubricants used for machining applications in order to enhance process performance.

The addition of nanometer-sized particles in suitable proportions to servo cut oil, canola oil, deionized water, coconut oil, vegetable oil, colza oil and soyabean oil used as coolants for machining of different materials like aerospace alloys, steel (of different grades), nickel based alloys etc. has proved to enhance the machining performance. Out of the many different nanoparticles, a number of oxides $\left(\mathrm{Al}_{2} \mathrm{O}_{3}, \mathrm{ZrO}_{2}, \mathrm{SiO}_{2}, \mathrm{TiO}_{2}, \mathrm{Fe}_{3} \mathrm{O}_{4}, \mathrm{ZnO}\right.$ and $\left.\mathrm{CuO}\right)$ with particle sizes ranging from $30 \mathrm{~nm}$ to $45 \mathrm{~nm}$, Graphene (nGr), CNT (Carbon Nanotube), nanodiamond (ND) and $\mathrm{MoS}_{2}$, are found to be suitable for maximum machining applications.

\footnotetext{
${ }^{1}$ Manufacturing and Materials Engineering, Opole University of Technology, Opole, Poland

*E:mail: w.grzesik@po.edu.pl

https://doi.org/10.36897/jme/133477
} 
The use of new coolant supply systems like MQL attempt to promote eco-friendly machining with a reduced use of coolants and hence the costs associated with machining.

The present review covers some important works done by researchers in the area of nanofluids. Fig. 1 shows a concept of investigations for the development of nanofluids for machining with MQL applications [3]. Recently nanoparticles mixed in conventional lubricants are used because of a remarkable improvement of thermo-physical and heat transfer capabilities which results in reducing friction and wear effects and causing the machining process to be more efficient and reliable [4]. The general concept of nanofluids results from the fact that effective applications of MQL techniques for machining need high thermal conductivity fluids in order to intensify heat dissipation from the cutting zone. Hence, the development of nanofluids for machining applications is strongly based on the investigations of their flow and heat dissipation. However, it was satisfactorily documented that nanoparticles as additives to coolants/lubricants combined with Minimum Quantity Lubrication systems could be useful in performing the machining operations with the reduction in cost and pollution.

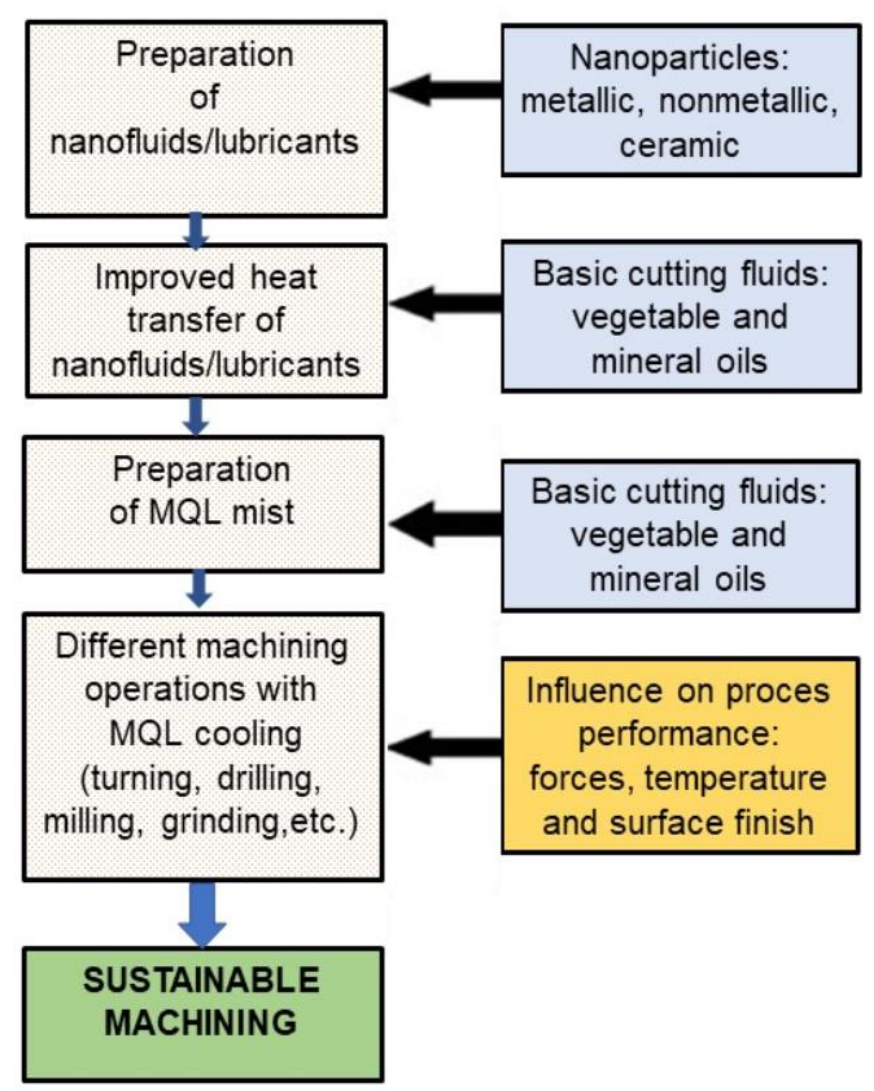

Fig. 1. A flow chart for investigations and development of nanofluids for machining applications [3]

Applications of nanofluids originated from micromachining but now they cover a number of machining operations such as milling, drilling and grinding using MQL technique [5]. In general, the strategy works well for hard-to-cut materials such as hardened steels, stainless steel, titanium-based and nickel-based superalloys or composite materials. 


\section{CHARACTERIZATION OF NANOFLUIDS}

From the definition, nanofluid is a fluid which contains nanometer-sized solid particles which provide efficient convective heat transfer and enhances the wettability in comparison to conventional fluids (CFs) $[4,6]$. It is important to note that a nanofluid can be produced by dispersing a typical size of less than $100 \mathrm{~nm}$ of metallic or non-metallic nanoparticles of nanofibers in a base liquid. The preparation of nanofluids is described in Ref. [4]. The combination of MQL and nanofluids is termed nano-fluid-assisted MQL (NFMQL) [7]. In general, the presence of nanoparticles in a base fluid contributes to a better flow of mixing and higher thermal conductivity compared to pure fluid. In this aspect, their contribution is similar to powders (predominantly $\mathrm{Al}_{2} \mathrm{O}_{3}$ particles) added to deionized water in EDM or electrolyte in ECM processes. Another point of view [8] related to $\mathrm{TiO}_{2}, \mathrm{Al}_{2} \mathrm{O}_{3}$, $\mathrm{Fe}$, and $\mathrm{WO}_{3}$ nanofluids is that the surface-to-volume ratio of nanoparticles is a dominant factor that influences the thermal conductivity of nanofluids. This is explained by the fact that surface-to-volume ratio is increased with smaller sizes of nanoparticles. However, nanofluids show a large enhancement of thermal conductivity compared with their base fluids, which exceeds the theoretical expectation of two-component mixture system. The effects of such factors as the stability of suspension of nanoparticles, nanoparticle size, and viscosity of base fluids should be taken into account.

Nano fluids, termed also engineered colloidal suspensions of nanofillers in a base fluid (MWF) may provide unique opportunities to enhance performance, especially in micromachining operations. In such cases the size of nano additives should allow their penetrating into the tool-chip contact when the typical cutting edge radius is in the 1-2 $\mu \mathrm{m}$ range and the depth of cut is less than $1 \mu \mathrm{m}$. In addition, they should also cover the small tool edge. Recently, carbon nanotubes (CNT) and graphene (nGr) additives (GPL - graphene platelets) were selected to enable the penetration of the tool-chip and tool-workpiece interfaces while also covering the cutting edge with an extremely small radius. This dimensional features (nanoscale thickness and microscale lateral dimension) in conjunction with excellent thermal properties (coefficient of thermal penetration (convection) is substantially higher than 1000 $\mathrm{W} / \mathrm{m}^{2} \mathrm{~K}$ - see Fig. 4) make nanofluids well-suited for changing the tribological and thermal conditions in the contact zones.

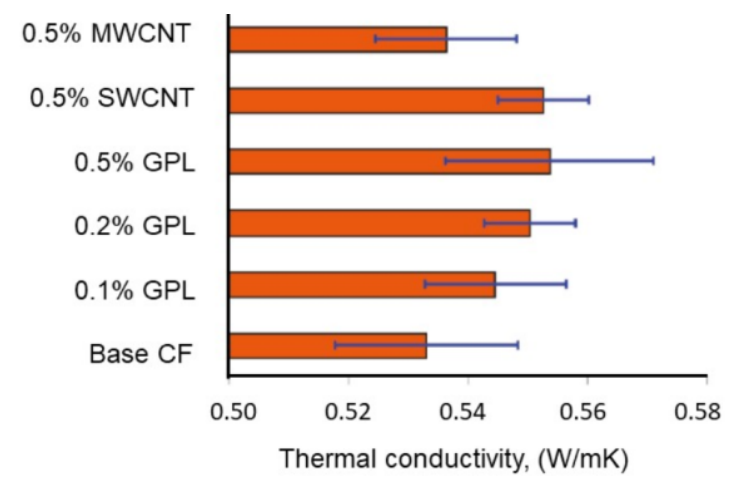

Fig. 2. Comparison of thermal conductivities for conventional (baseline) and various nano-fluids [9], Symbols: MWCNT - multi-walled nano-carbon tube, SWNCT - single-walled nano-carbon tube, GPL - graphene platelets 
It is evident from Fig. 2 that the nanofluid with high concentration of nano-additives (nano-fillers), for instance $0.5 \mathrm{wt} \% \mathrm{SWCNT}$ and $0.5 \mathrm{wt} \%$ GPL, causes that the thermal conductivity of nanofluid mist increases substantially in comparison to the base semisynthetic fluid used.

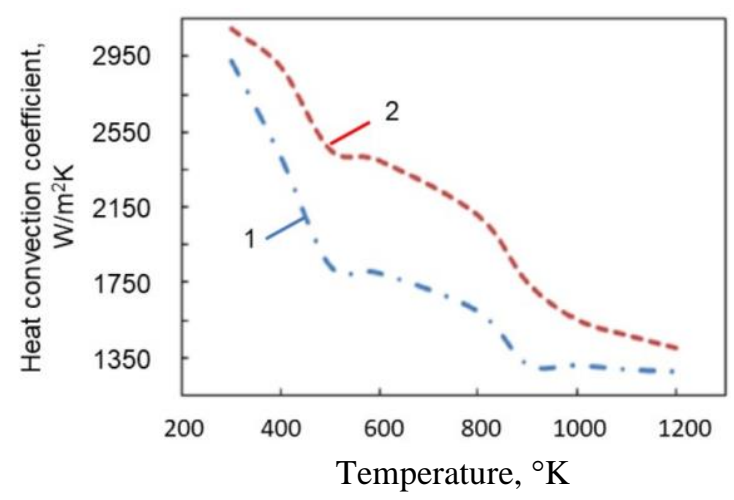

Fig. 3. The average heat convection coefficient results versus temperature for varying percentage of MWCNTs [10], Symbols: $1-2 \%$ wt, $2-4 \%$ wt

In Ref. [5] a computation fluid dynamics (CDF) model was used to simulate the behavior of MQL nano-fluid flow and surrounded air (two-phase flow domain). In this successful modelling the average heat convention coefficient at temperature ranging from $200^{\circ} \mathrm{K}$ to $1200^{\circ} \mathrm{K}$ was used as presented in Fig. 3. It should be noted that the distribution of the heat convention is non-linear and distinctly higher values are expected for the concentration of MWCNT $-4 \%$ wt [11].

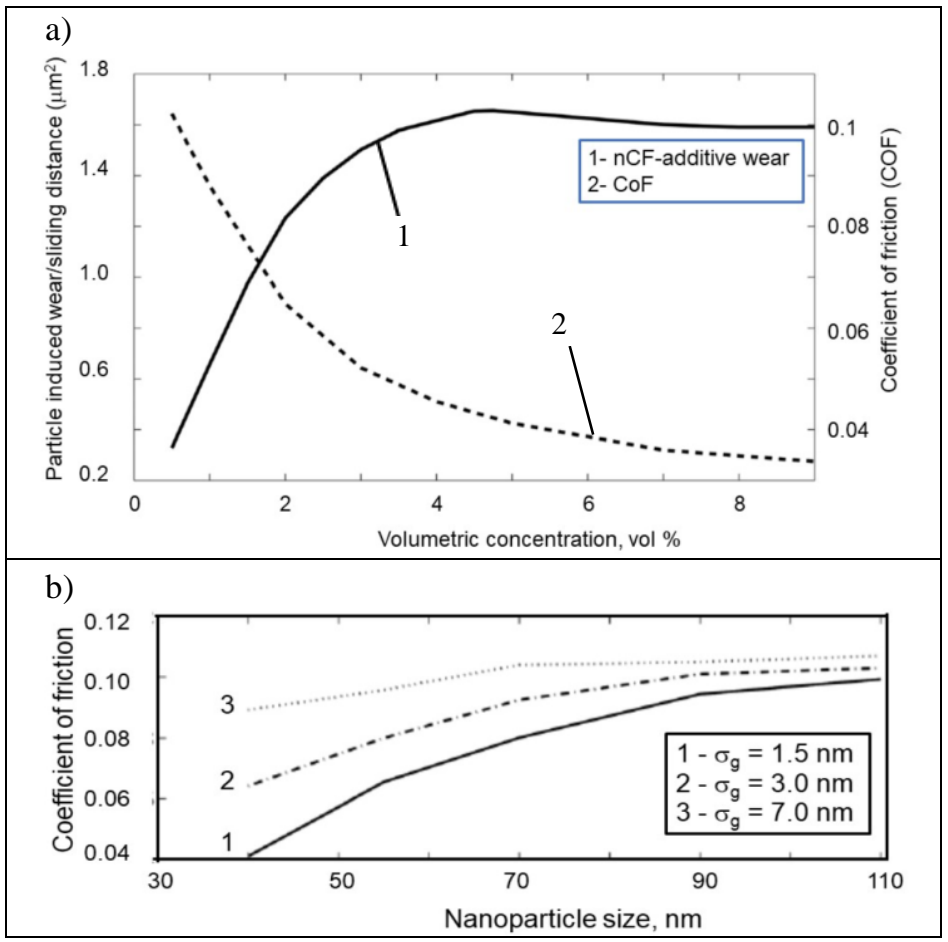

Fig. 4. Influence of the nano-additive volume concentration on the particle induced wear and COF (a) and nanoparticle size on COF [12] (b) 
It was documented $[11,13]$ that nano-additives increased wear along with increasing their concentration as shown in Fig. 4a. On the other hand, under such lubrication conditions the resultant nano-fluid conductivity increases which improves the heat dissipation from the cutting zone. However, increasing the concentration of nano-additives in the tool-chip interface causes that the effective contact area also increases and finally the apparent friction can be reduced (course \#2 in Fig. 4a). Course \#1 in Fig. 4a indicates that the evolution of additional wear, defined as the ratio $\left(V_{n p} / L_{d}\right.$ where $V_{n p}$ is the particle induced volumetric wear and $L_{d}$ is the sliding distance), due the rolling and sliding movement of nano-additives on the contact tool surfaces, which is more intensive when their concentration increases [14]. Moreover, the COF depends on the standard deviation (SD) of the particle distribution in such a way that less SD results in a higher COF value (Fig. 4b). These important thermal and triboeffects suggest that the concentration of nano-additives should be carefully selected in terms of process performance.

\section{NANOFLUID MECHANISMS IN MACHINING}

In the case of MQL-nano-cutting fluid two main mechanisms of the influence on the tribo-contact at the tool-chip interface can be distinguished $[11,10]$. They are schematically illustrated in Fig. 5.

a)

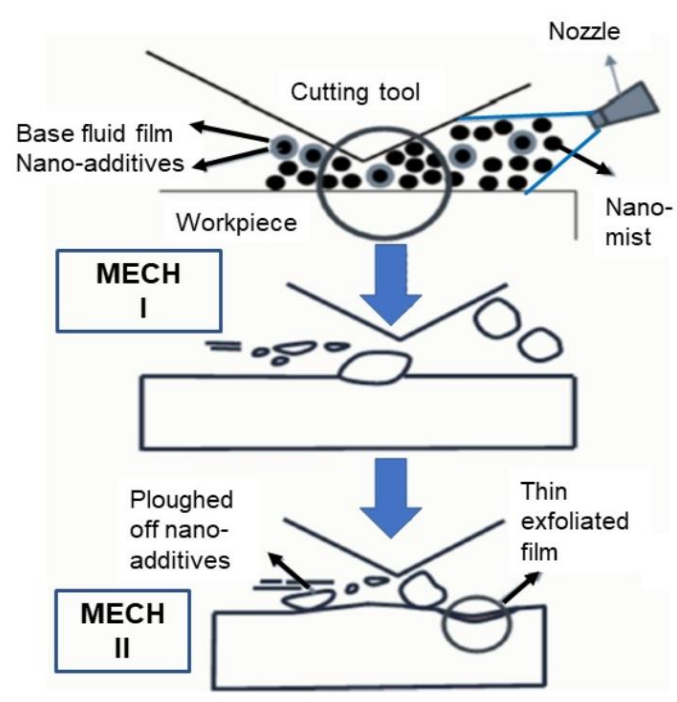

b1)

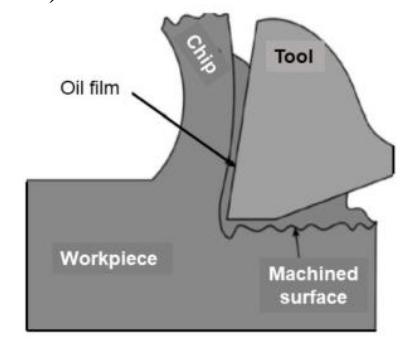

b2)

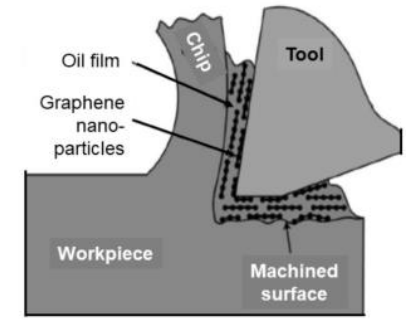

Fig. 5. The MQL-nano cutting fluid mechanism (rolling and ploughing) [10, 11], a) schematic illustration of the contact zones for different cooling/lubrication conditions: b1) conventional MQL, b2) graphene-assisted MQL [15]

The first rolling mechanism is developed in the following way:

- The fine mist is produced by shearing and breaking nano-additives under high velocity of the compressed air accelerated in the MQL nozzle. This process is called atomization (see Fig. 6). 
- The mist plays a role of a thin film of nano-particles and is able to penetrate to the tool-chip contact because its velocity is higher than the cutting tool velocity. In particular, nano-particles penetrate to the tool surface pores and grain fractured grooves on the machined surface.

- During cutting both the cutting tool and machined surfaces are occupied intensively by nanofluid droplets. As a result, a stable tribo-film, which substantially reduces friction and moderates wear behaviour is formed.

- When the concentration of nano-additives increases further also the density of nanofluid in the cutting area increases. Finally, it causes that nano-particles and nano-tubes act as a nano-rollers and reduce friction in the contact zones.

The second ploughing mechanism is developed in the following way:

- As mentioned above nano-particles or nano-tubes are intensively attached the workpiece surfaces and due to the high pressure they are sheared off in spite of their predominant rolling effect.

- The effect of the high compression pressure and parallel increased loading of the highly concentrated nano-particles/nano-tubes is that their shapes change which causes shearing rather than rolling behavior. Moreover, it is observed that some nanoparticles are washed away and swept by the fresh nanofluid supplied to the cutting zone.

- The mechanical cutting loads can increase when some nano-particles are embedded in the surface grooves. They are cut off by other nano-particles and additionally, the large amount of nano-particles is cumulated in the grooves between surface asperities. In this aspect, higher cutting loads resulting from nano-particles getting stuck in the grooves do not seem convincing.

- A specific phenomenon occurs in which a film formed from nano-particles covers the machined surface causing a shielding effect for heat dissipation into the workpiece. Consequently, the elasto-hydrodynamic conditions are transformed into the boundary lubrication.

When the nanofluid mist is dispersed in the cutting zone, a number of nano-particles are embedded into the machined surface. As a result, some nano-particles cause a rolling effect, while others more connected with the surface are sheared from it due to high pressure developed in the cutting zone, i.e. ploughing effect is the predominant mechanism. However, in the first stage of machining a very fine nano-additives layer is formed at the tool-chip interface but as the machining proceeds the growth of the shielding layer on the machined surface is observed. It should be observed in Fig. 5 that nano-additives work as spacers which limit the induced rubbing effect between the contact surfaces of the workpiece and the tool. Also, the ploughed-off effect causes that nano-additives leave a thin exfoliated film which plays a protective role in decreasing the generated heat transfer into the workpiece.

Figure 6a shows the experimental setup for the micromachining operation in which atomized fluid droplets are delivery into the cutting zone. The MQL delivery system consists of an ultrasonically vibrating piezoelectric transducer attached to the cutting fluid reservoir. Atomized droplets are generated by US vibrations and transported to a delivery pipe. The required air velocity is regulated by a coaxial air tube and the atomized droplets are consequently transported into the cutting zone. A three-axis micro-machine tool equipped 
with a high speed spindle of $50000 \mathrm{rpm}$, capable of performing microturning operations with the assistance of nano fluids is used. Semisynthetic cutting fluid as the baseline cutting fluid with GPL additives of $0.1,0.2$ and $0.5 \%$ wt is applied.

a)

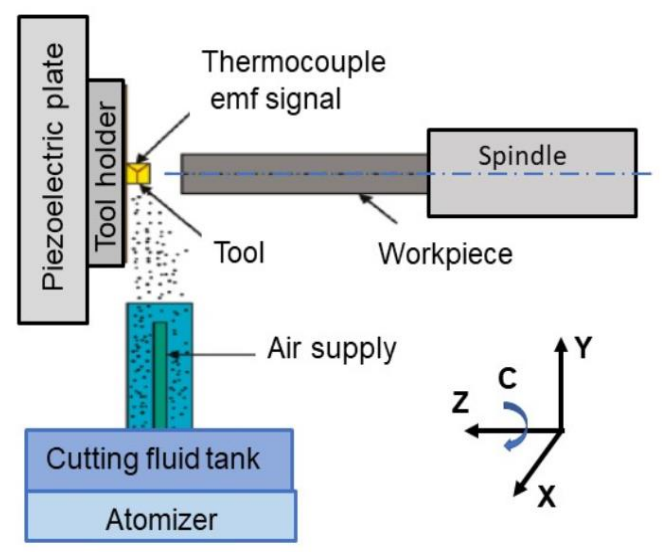

b)

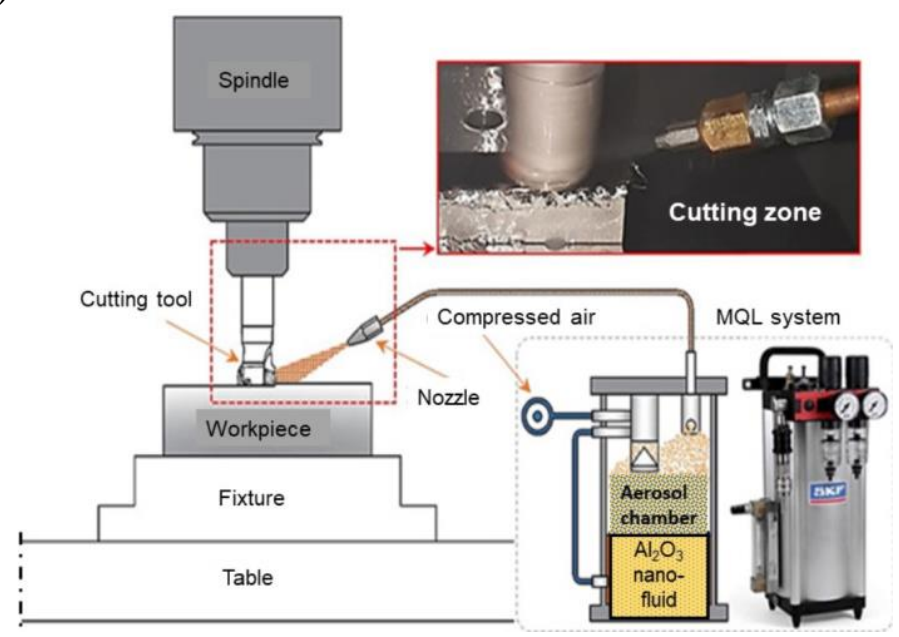

Fig. 6. Experimental setup for microturning operation using nanofluid with transportation of atomized droplets [7] (a) and nanofluid MQL supply system in milling [16, 17] (b)

Figure $6 \mathrm{~b}$ presents the experimental setup for nanofluid MQL tests equipped with a CNC vertical milling machine and a commercial MQL system which delivers the nanofluid together with pressured air to the machining zone in a pulverized way. The following optimal parameters of the nanofluid supply were used: the vegetable oil flow rate of $100 \mathrm{ml} / \mathrm{h}$, spray angle of $45^{\circ}$ and spray pressure of 8 bar. During milling tests the nanofluid with different concentration of $0.5 \%, 1 \%$ and $1.5 \%$ by volume of $\mathrm{Al}_{2} \mathrm{O}_{3}$ nanoparticles was used. The procedure for preparation of a homogeneous mixture is described in Ref. [14].

\section{PROCESS CHARACTERISTICS WITH NANOFLUID ASSISTANCE}

\subsection{CUTTING TEMPERATURE}

Figure 7 shows the distribution of temperature along the tool-chip contact area which indicates the significant decreasing the temperature in the machining of Inconel 718 and Ti6Al4V titanium alloys when using MQL-nanofluid supply in comparison to pure MQL method. In this case MWCNs (multi walled carbon nanotubes) nanofluid was used with $2 \%$ wt and 4\%wt concentration of MWCNTs. It can be seen in Fig. 7 that for 4\%wt concentration of MWCNTs the contact temperature is constant at the value of about $500^{\circ} \mathrm{K}$ (Fig. $7 \mathrm{a}$ ) and $600^{\circ} \mathrm{K}$ (Fig. $7 \mathrm{~b}$ ). In the case of titanium alloy the distribution of the cutting temperature is similar to the distribution of shear stress along the tool-chip interface $\left(l_{c}\right)$ [16]. 


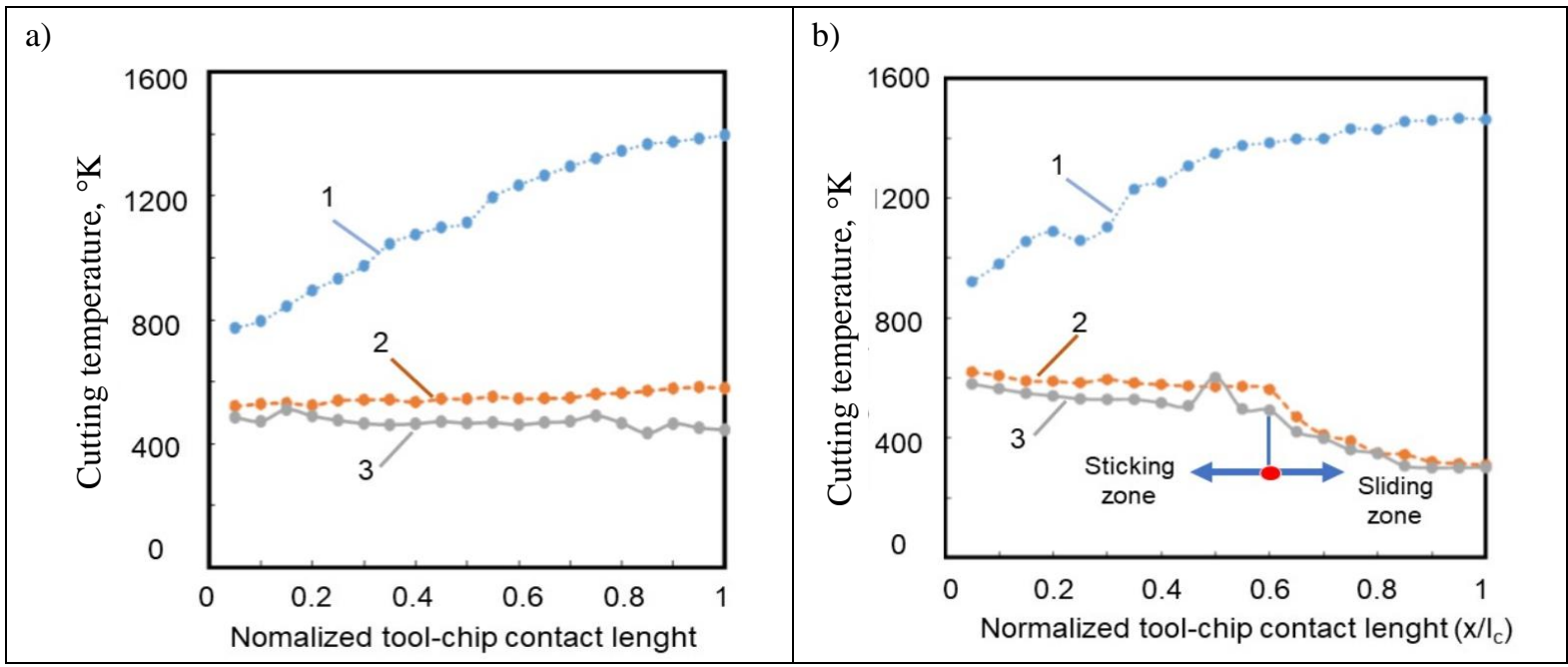

Fig. 7. The temperature distribution along the chip-tool interface with/without MWCNTs-nano-fluid during machining of Inconel 718 alloy (a) and Ti6Al4V alloy (b) [11], Symbols: 1 - without nanofluid, 2 - with nanofluid and $2 \%$ wt concentration, 3 - with nanofluid and $4 \%$ wt concentration

Figure 8a shows comparatively the records of cutting temperature for the baseline $\mathrm{CF}$ and three various weight fractions of GPL $(0.1,0.2$ and $0.5 \mathrm{wt} \%)$ which were added to the CF. It is evident that GPL additives influence significantly the peak temperature and suppress it during the cut. The most visible effect was recorded for the highest fraction of $0.5 \%$ wt GPL in the colloidal suspension. Moreover, temperature fluctuations for nanofluids with the GPL particles are smaller than for the base semi-synthetic CF. These evidences suggest that the GPL additives penetrate into the tool-chip interface and reduce friction and interface temperature.

a)

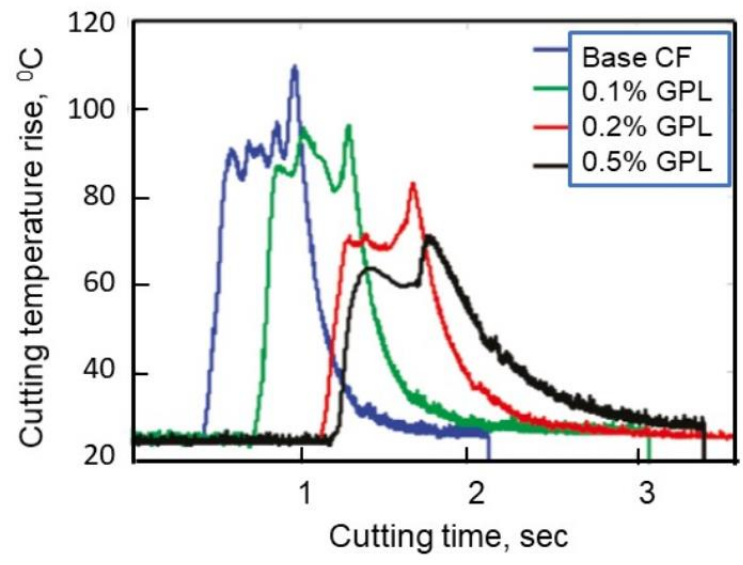

b)

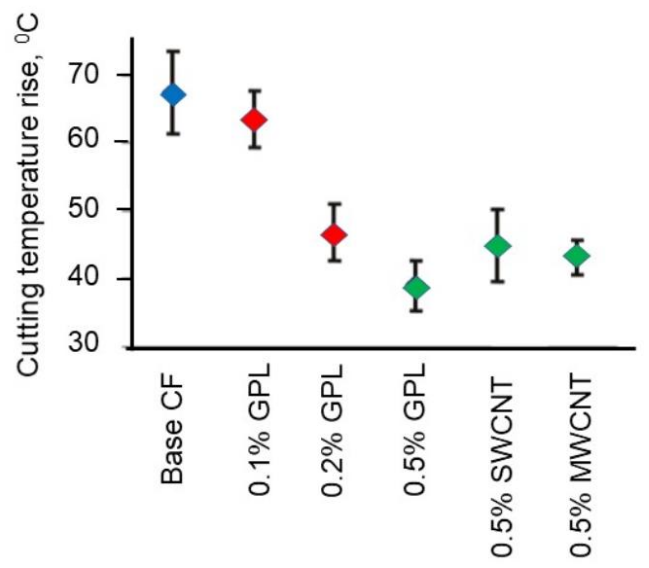

Fig. 8. Typical traces of the cutting temperature vs. time for the microturning operations performed using the experimental setup from Fig. 4 (a) and cutting temperature rise (b) [9]

Figure $8 \mathrm{~b}$ shows relevant increments of the cutting temperature recorded by a thermocouple method (see Fig. 4) during the micromachining tests. It is clear that addition of graphene to the base fluid reduces the interface temperature on the rake face. The addition 
of $0.1,0.2$ and $0.5 \mathrm{wt} \%$ of graphene results in decreasing the reference temperature of about $70^{\circ} \mathrm{C}$ by about 6,30 and $40 \%$ respectively. However, the influence of $0.5 \%$ SWCNT and $0.5 \%$ MWCNT is similar to the previously quantified graphene nano-fillers.

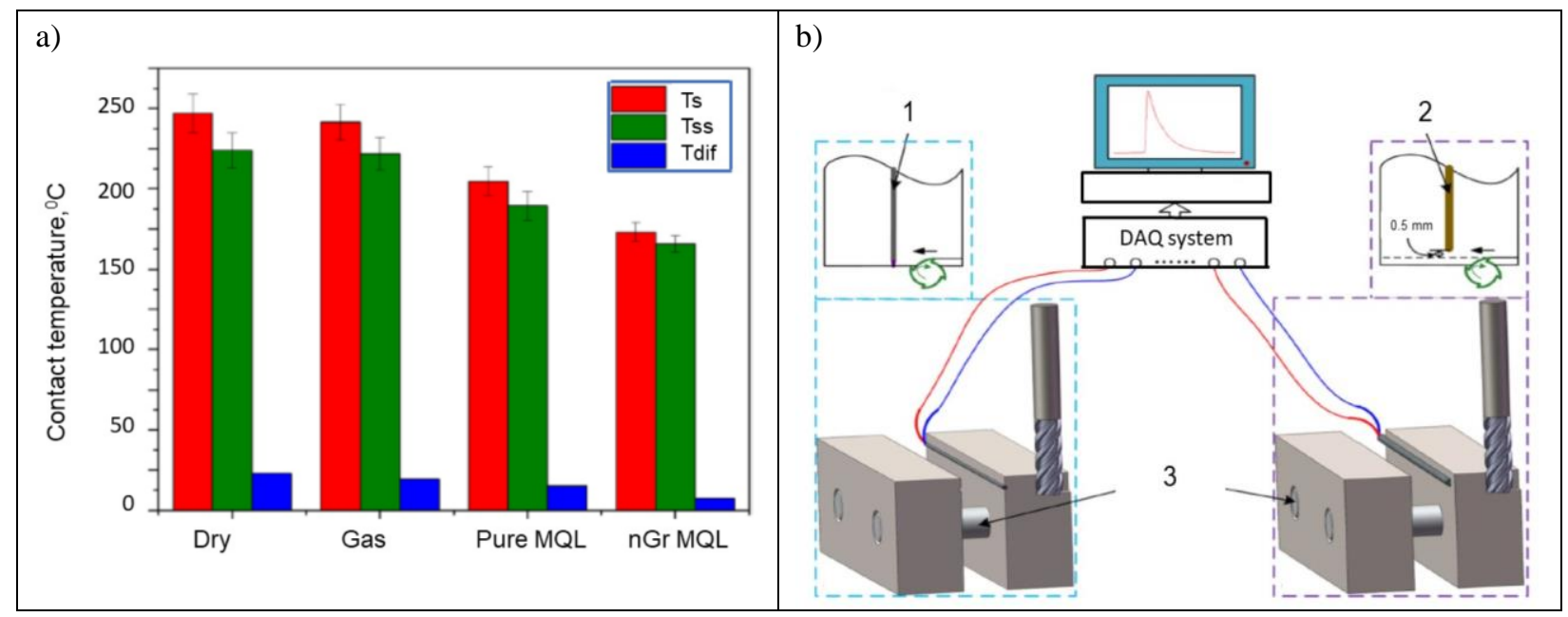

Fig. 9. Maximum surface and subsurface values of temperature for different cooling/lubrication conditions (a) and measurement strategy (b) [15], Symbols: $T_{\mathrm{s}}$ - surface temperature, $T_{\mathrm{ss}}-$ subsurface temperature, $T_{\mathrm{dif}}-$ temperature difference, 1 -K-type thermocouple, 2 - K-type armored thermocouple, 3 - positioning pin

Figure 9a presents the maximum values of surface and subsurface temperatures measured in end-milling operations of a titanium alloy for different cooling/lubrication techniques including dry, gas assisted, MQL and nano-fluid MQL cases. As shown in Fig. 9b the temperature measurements were performed using commercial K-type thermocouple and K-type armored thermocouple probe were inserted into $0.3 \mathrm{~mm}$ and $1.0 \mathrm{~mm}$ diameter holes in the workpiece respectively [15]. Conventional milling trials were carried out on a 4-axis CNC machining center using a TiAlN coated solid end-mill.

As can be seen in Fig. 9 the maximum temperatures for dry cutting are equal to about $250^{\circ} \mathrm{C}$ and $225^{\circ} \mathrm{C}$ respectively. They are slightly reduced by about $2 \%$ when using gaseous cooling medium. More pronounced reduction of the temperatures to about $205^{\circ} \mathrm{C}$ and $190^{\circ} \mathrm{C}$, i.e. about $15.5 \%$ in relation to dry condition, are recorded for MQL. Further reduction of the maximum temperatures to about $175^{\circ} \mathrm{C}$ and $165^{\circ} \mathrm{C}$, i.e. about $30 \%$, are recorded for nanofluid MQL. In this case, the minimum difference between surface and subsurface temperatures is determined.

\subsection{TOOL WEAR AND TOOL LIFE}

It has previously been mentioned many times that nano-fluids reduce friction and, as a result slows down tool wear. To confirm this hypothesis Fig. 10 presents the wear scars detected during machining of Inconel 718 alloy under nano-cutting fluid MQL using different nano-additives (alumina nanoparticles $\left(\mathrm{Al}_{2} \mathrm{O}_{3}\right)$ and multi-walled carbon nanotubes (MWCNTs)) and their concentrations. The wear observations cover both flank and rake face. 


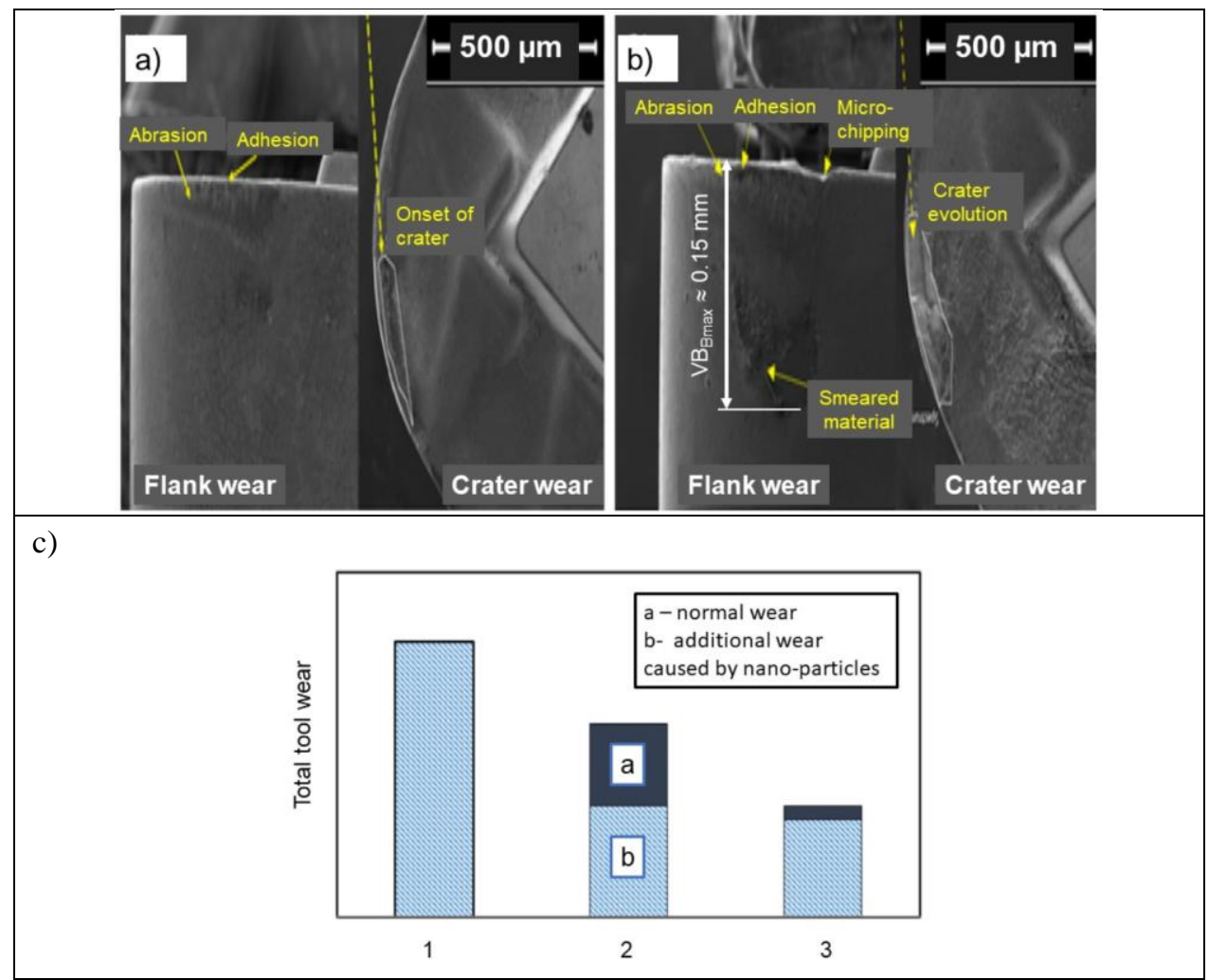

Fig. 10. Comparison of tool wear mechanisms with MQL nanofluid (a) and with classical MQL supply (b);

(c) components of nano-additives induced wear, 1 - without nano-particles, 2 - with nano-particles, 3 - with carbon nanotubes, Cutting parameters: cutting speed of $170 \mathrm{~m} / \mathrm{min}$, feed rate of $0.15 \mathrm{~mm} / \mathrm{rev}$, workpiece material - Ti6Al4V titanium alloy [10, 13]

Figure 10 shows the tool wear mechanisms for two cases. In general, in both cases the abrasive wear results from a rubbing between the tool and the chip and the machined surface. It is evident in Fig. 10b that abrasive wear is more intensive at the flank and rake faces after cutting with using classical MQL system. In contrast, thanks to the MQL nanofluid effect, a noticeable reduction of the abrasion wear at both flank and rake faces of the cutting insert was observed as shown in Fig. 10a. This fact confirms that the used nanofluids improve the heat transfer and frictional behavior at the contact zones. On the other hand, as mentioned in Section 2, additional tool wear caused by the nano-additives should be considered [6]. It is more pronounced for nano-particles, as for instance for hard $\mathrm{Al}_{2} \mathrm{O}_{3}$ ceramic particles, than for carbon nanotubes.

The results of tool wear test concerning the cutting process with MWCNTs and $\mathrm{Al}_{2} \mathrm{O}_{3}$ nano-fluids are shown in Fig. 11. Conventional turning trials were carried out using a TiAlN coated carbide inserts and a MQL Eco-Lubric system with a nominal flow rate of $40 \mathrm{ml} / \mathrm{hr}$. The tool wear criterion was the maximum flank wear $\mathrm{VB}_{\mathrm{Bmax}}=0.4 \mathrm{~mm}$. In general, the applications of nano-fluids causes that flank wear decreases in relation to tests without any nanoadditives (tests \# 1, 6 and 8). The lowest flank wear of about $0.15 \mathrm{~mm}$ was obtained for the use of $2 \%$ wt MWCNCT-based nano-fluids (test \#2) when $v_{\mathrm{c}}=30 \mathrm{~m} / \mathrm{min}$ and $f=0.3 \mathrm{~mm} / \mathrm{rev}$. On the other hand, the lowest flank wear of about $0.17 \mathrm{~mm}$ was indicated for $4 \% \mathrm{wt} \mathrm{Al}_{2} \mathrm{O}_{3}$ based nano-fluid (test \#3) when $v_{\mathrm{c}}=40 \mathrm{~m} / \mathrm{min}$ and $f=0.2 \mathrm{~mm} / \mathrm{rev}$. In contrast, the highest tool wear was detected for test \# 8 when the feed rate was increased to $0.4 \mathrm{~mm} / \mathrm{rev}$. 
The general conclusion is that the nano-fluids significantly improve cooling and lubrication conditions at the tool-chip interface and around the cutting edge. Therefore, the tool wear is reduced.

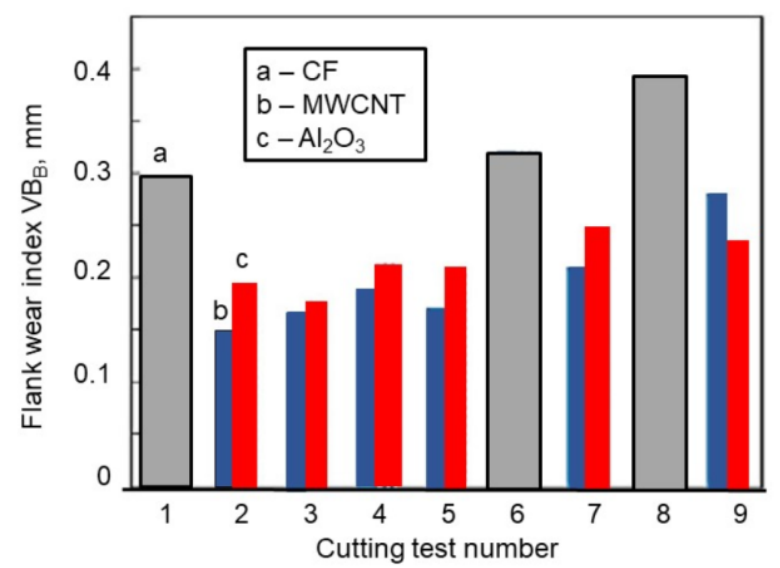

Fig. 11. Comparison of flank wear land $\left(\mathrm{VB}_{\mathrm{B}}\right)$ for different cooling modes when machining Inconel 718 alloy [13], Cutting parameters: cutting speed: 1,2 and $3-30 \mathrm{~m} / \mathrm{min} ; 4,5$ and $6-40 \mathrm{~m} / \mathrm{min} ; 7,8$ and $9-50 \mathrm{~m} / \mathrm{min}$; feed rate; 1,2 and $3-0.2,0.3$ and $0.4 \mathrm{~mm} / \mathrm{rev} ; 4,5$ and $6-0.2,0.3$ and $0.4 \mathrm{~mm} / \mathrm{rev} ; 7,8$ and $9-0.2,0.3$ and $0.4 \mathrm{~mm} / \mathrm{rev}$; depth of cut: $0.2 \mathrm{~mm}$

Figure 12 presents the results of tool wear tests performed in the turning operations using Inconel 800 alloy as the workpiece material and CBN tool with rhombic shape. A CNC lathe equipped with a MQL "NOGA mini cool system" was used. As can be seen in Fig. 12, graphite-based nanofluid causes that tool wear is reduced more than for $\mathrm{Al}_{2} \mathrm{O}_{3}$ and $\mathrm{MoS}_{2}$ nano-additives. This is due to the fact that giant covalent structure in graphite atomic structures leads to a better rolling effect which reduces friction, especially in comparison to the alumina atomic structure [7]. However, the visible effect is observed for the cutting speed higher than $250 \mathrm{~m} / \mathrm{min}$ (see Fig. 12).

Table 1 summarizes some literature data concerning the tool life enhancement when using different nanofluids such as $\mathrm{Al}_{2} \mathrm{O}_{3}, \mathrm{TiO}_{2}, \mathrm{CuO}, \mathrm{MWCNT}$ and nGr. The range of toollife increment varies from about $20 \%$ up to $600 \%$ depending on the workpiece grade and machining conditions employed. In general, nanofluids enhance tool life period.

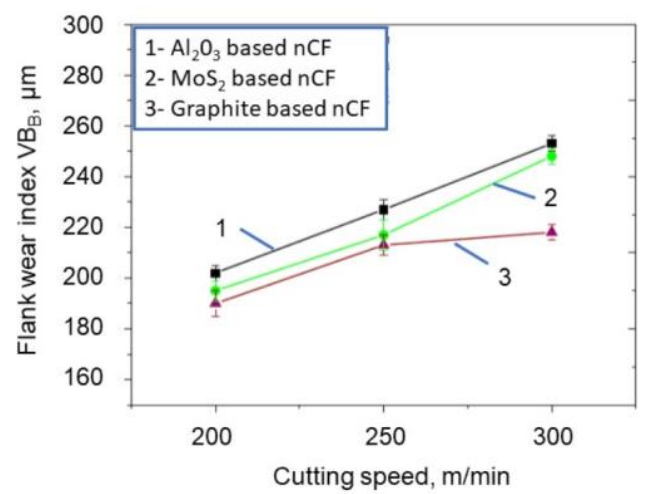

Fig. 12. Influence of cutting speed in the machining of Inconel 800 alloy using different nanofluids $\left(\mathrm{Al}_{2} \mathrm{O}_{3}, \mathrm{MoS}_{2}\right.$ and graphite-based ones) [7], Cutting parameters: $f=0.15 \mathrm{~mm} / \mathrm{rev}, a_{\mathrm{p}}=0.50 \mathrm{~mm}$ ) 
Table 1. Tool life enhancement when using different nano-fluids [18]

\begin{tabular}{|l|c|}
\hline Kind of nanofluid & Resulting tool life \\
\hline Mineral oil plus $\mathrm{CuO}$ nano-additives & Up to about $600 \%$ \\
Soybean oil plus $\mathrm{Al}_{2} \mathrm{O}_{3}$ nano-additives & About $180 \%$ \\
Vegetable oil plus $\mathrm{Al}_{2} \mathrm{O}_{3}$ nano-additives & Above $20 \%$ \\
Vegetable oil plus $\mathrm{Al}_{2} \mathrm{O}_{3} / \mathrm{MWCNT}$ nano-additives & Visible effect \\
Deionized water plus $\mathrm{TiO}_{2}$ nano-additives & About $70 \%$ \\
Ethylene glycol plus $\mathrm{TiO}_{2}$ nano-additives & Prolonged tool life period \\
Vegetable oil plus graphene nano-additives & About $180 \%$ \\
\hline
\end{tabular}

\subsection{SURFACE ROUGHNESS}

The third group of possible influences of nanofluids concerns the surface roughness produced during NFMQL processes. Overall, the surface quality improves when machining is performed with a nanofluid MQL system rather than dry machining or pure MQL. It results from the fact that nanoparticles create a protective layer in the tool-workpiece interface. It should be noted in Fig.13 that the surface roughness parameter (Ra) obtained for dry and gasassisted milling is equal to about $0.65 \mu \mathrm{m}$ but it is substantially reduced to about $0.42 \mu \mathrm{m}$ and $0.31 \mu \mathrm{m}$ when applying conventional MQL and nano-fluid assisted MQL respectively. That means that the Ra value measured for dry machining is reduced by $53 \%$ when using graphene MQL conditions. The main reason is that the oil films are formed in the milling zone under the pure MQL and nano-fluid MQL conditions when graphene nano-additives are additionally added to the oil-air mist.

Figure 14 reveals that the surface roughness of $\mathrm{Ra}=0.08-0.2 \mu \mathrm{m}$ (equivalently $\mathrm{Rz}=$ $0.5-1.5 \mu \mathrm{m}$ ) is produced in hard face milling operations on a $60 \mathrm{Si} 2 \mathrm{Mn}$ steel of about $50 \mathrm{HRC}$ hardness in which $\mathrm{Al}_{2} \mathrm{O}_{3}$ nanoparticles with the volumetric concentration of $0.5 \%$ are added to emulsion of 5\% coolant. It should be noted that nano-fluid causes that the surface roughness is stable during first $60 \mathrm{~min}$ of the milling test. After next $60 \mathrm{~min}$ it increases up to $0.2 \mu \mathrm{m}$ due to milling cutter wear to $\mathrm{VB}_{\mathrm{B}}=0.4 \mathrm{~mm}$ [18].

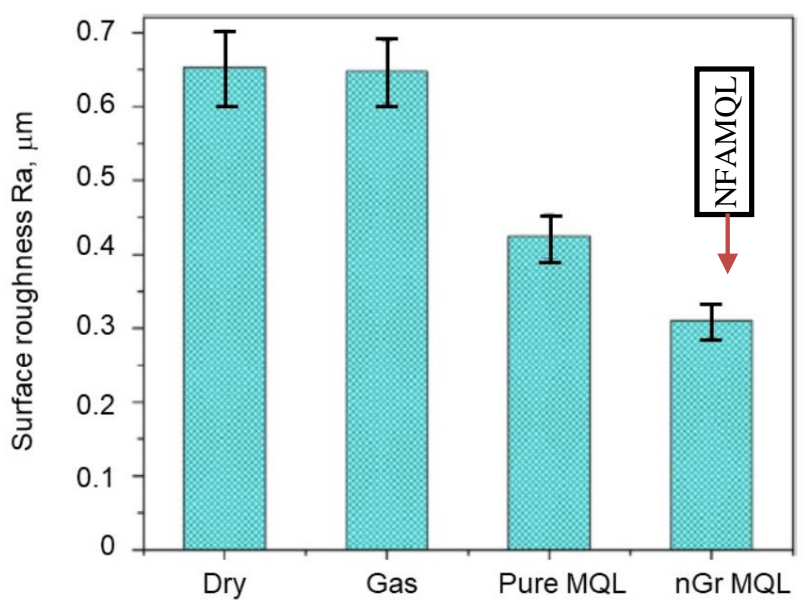

Fig. 13. Surface roughness measured for milling surfaces under different cooling/lubrication conditions [15] 


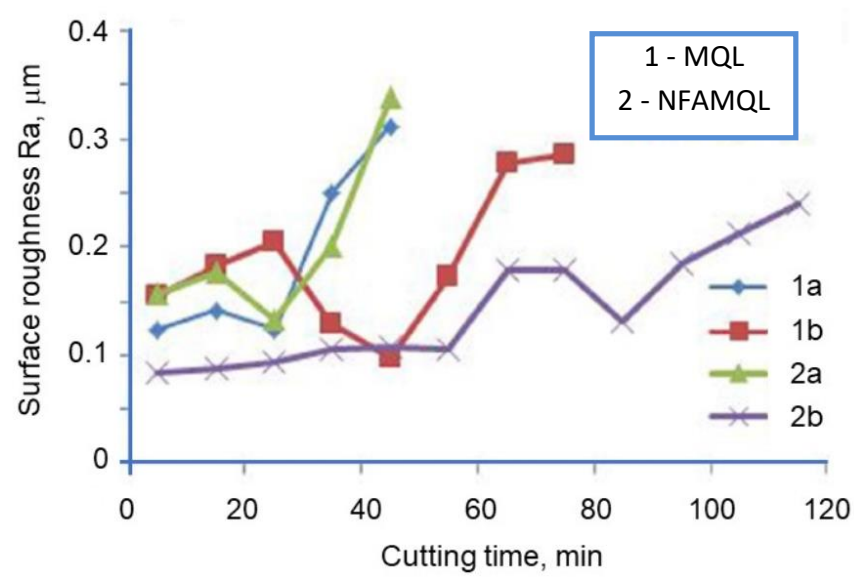

Fig. 14. Surface roughness vs. cutting time measured for milled surfaces under MQL conditions with or without nanofluids [19], Symbols: $1 \mathrm{a}$ - soybean oil (SO), $1 \mathrm{~b}-$ emulsion (E), $2 \mathrm{a}-\mathrm{SO}+0.5 \% \mathrm{nCF}, 2 \mathrm{~b}-\mathrm{E}+0.5 \% \mathrm{nCF}$

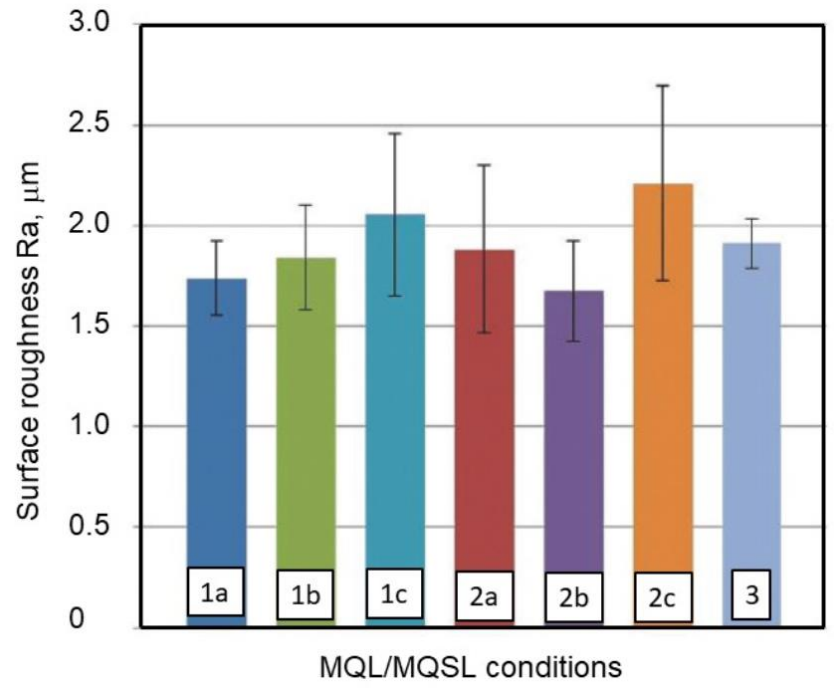

Fig. 15. Surface roughness measured for turned surfaces when machining Inconel 718 under MQL and MQSL conditions [20], Cutting conditions: $\mathrm{v}_{\mathrm{c}}=100 \mathrm{~m} / \mathrm{min}, \mathrm{f}=0.15 \mathrm{~mm} / \mathrm{rev}, \mathrm{a}_{\mathrm{p}}=1.5 \mathrm{~mm}$, Symbols: $1-$ flow rate of $40 \mathrm{ml} / \mathrm{h}$,

2- flow rate of $250 \mathrm{ml} / \mathrm{h}, 3$ - flood cooling, a - pure MQL, b-MQSL with $20 \% \mathrm{Gr}$, c-MQSL with $20 \% \mathrm{MoS}_{2}$

Figure 15 compares the Ra values measured after pure MQL and MQSL (minimum quantity solid lubrication) when solid lubricant in the form of nanoparticles of graphite (40 $\mu \mathrm{m}$ in size) and $\mathrm{MoS}_{2}(6 \mu \mathrm{m}$ in size) in the $20 \%$ volumetric concentration are added to MQL vegetable-oil-based fluid. Two flow rates of MQL supply equal to $40 \mathrm{ml} / \mathrm{h}$ and $250 \mathrm{ml} / \mathrm{h}$ are used in the turning of Inconel 718 alloy [20]. The main practical evidence observed in this comparative study is that the minimum surface roughness $\mathrm{Ra}$ of $1.67 \mu \mathrm{m}$ was measured when using MQSL system with $20 \%$ graphite nano-additives and the flow rate of $250 \mathrm{ml} / \mathrm{h}$. However, the Ra value increases slightly to $1.84 \mu \mathrm{m}$ when lower flow rate of $40 \mathrm{ml} / \mathrm{h}$ is applied. In case of $\mathrm{MoS}_{2}$ nano-additives the equivalent $\mathrm{Ra}$ values are equal to $2.20 \mu \mathrm{m}$ and $2.05 \mu \mathrm{m}$. In general, the differences between Ra values obtained for pure MQL and MQSL systems are not decisive. However, the nano-fluid MQL/MQSL can effectively replace flood cooling. 
Figure 16a presents the comparison of surface roughness parameter ( $\mathrm{Ra}$ ) for ground surfaces using dry air, pure MQL and nano-fluid MQL methods. It can be noted in Fig. 16a that the largest enhancement in surface roughness $(\mathrm{Ra} \approx 0.1 \mu \mathrm{m})$ was determined in the case of nanofluid MQL with paraffin oil as a base fluid and nano-diamond additives of $30 \mathrm{~nm}$ in the size and volumetric concentration of $2 \%$. Similar result was obtained for nano- $\mathrm{Al}_{2} \mathrm{O}_{3}$ particles of the same size and volumetric concentration [21]. The explanation of this final effect is that smaller nanoparticles are absorbed more intensively in the grinding area and the above mentioned rolling effect (Section 2) seems to be more pronounced.

Figure 16b presents SEM micrographs of micro-drilled holes produced with nanofluid MQL assistance. Cases (1 and 2) concern nanofluid with paraffin oil and 1 vol\% of nanodiamond particles, and with vegetable oil and 2 vol\% of nano-diamond additives respectively. It is evident that extremely hard nano-diamond particles effectively remove burrs which were formed around the circumference of the drilled holes and prevent the adherence of chips to the micro-drill used.

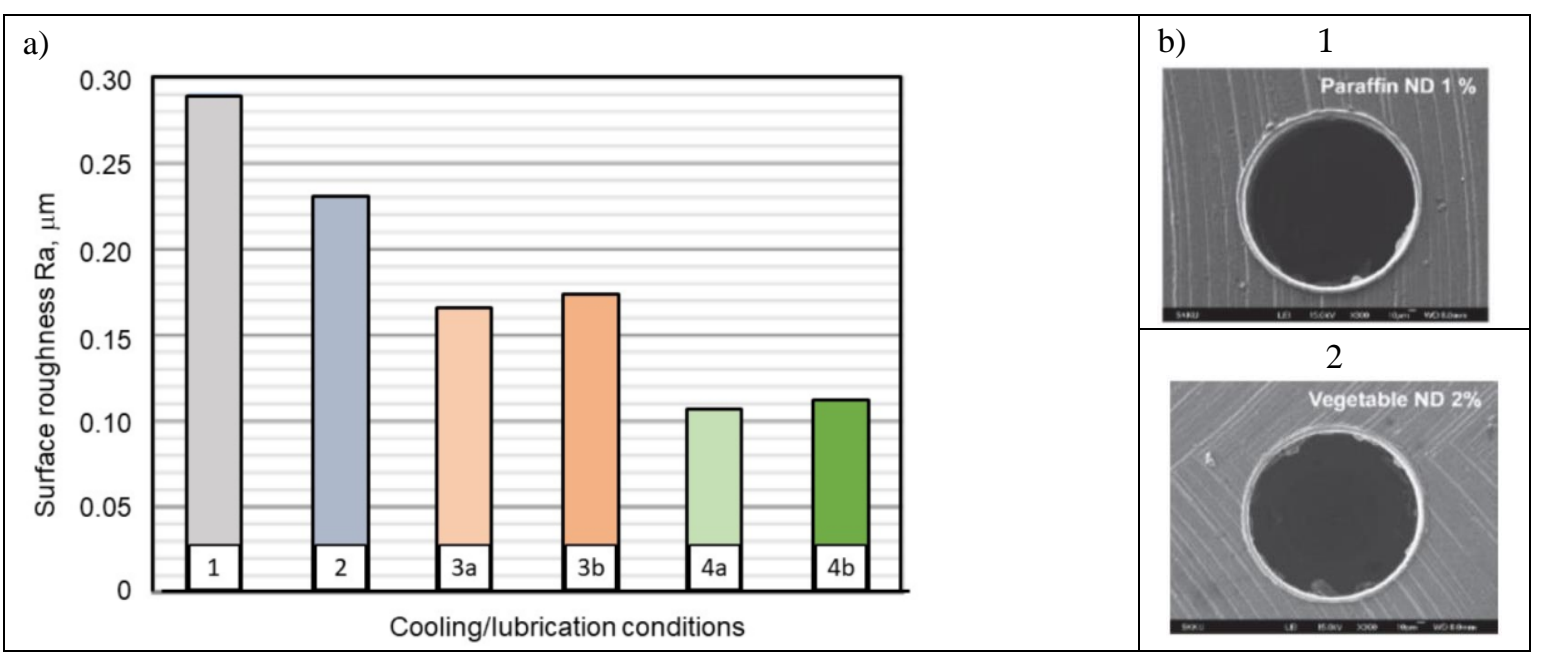

Fig. 16. Surface roughness measured for micro-ground (a) and micro-drilled hole surfaces under different cooling/lubrication conditions (b) [14, 20], Workpiece material: SK41C tool steel (a) and 6061 aluminium grade (b), Symbols: 1 - dry air, 2 - pure MQL, 3 - MQL with $150 \mathrm{~nm}$ nano-diamond (ND) particles, 4 - MQL with $30 \mathrm{~nm}$ ND particles, $\mathrm{a}-2 \%$ ND concentration, $\mathrm{b}-4 \%$ ND concentration

\section{CONCLUSIONS}

1. Machining assisted by nanofluids enhances the performance of machining processes in such important aspects as cutting temperature, friction and wear. As a result, surface finish is substantially improved.

2. Nano-fluids improve substantially wettability of the contacted surfaces, enhance thermal conductivity and provide efficient convective heat transfer in comparison to conventional fluids.

3. Two main mechanisms of the influence of nano-additives in the CFs include rolling and ploughing mechanisms. The first mechanism causes that nano-particles and nano-tubes 
act as a nano-rollers and reduce friction in the contact zones. The second mechanism causes that nano-additives leave a thin exfoliated film which plays a protective role in decreasing the generated heat transfer into the workpiece.

4. Among many nano-additives tested, the best performance was determined when adding both graphene (nGr) and MWCNTs particles to pure cutting fluids. Less effect is reported when adding nano $\mathrm{Al}_{2} \mathrm{O}_{3}$ particles. It should be noted that the concentration of nanoadditives is very important in achieving the optimal process performance.

5. Sustainability of nanofluid MQL is extended to savings not only in terms of environmental protection and energy consumption, but also for costs and time due to prolonged tool life.

\section{REFERENCES}

[1] LAUWERS B., KLOCKE F., KLINK A., TEKKAYA A.E., NEUGEBAUER R., MCINTOSH D., 2014, Hybrid Processes in Manufacturing, Annals of the CIRP Manufacturing Technology, 63/2, 561-583.

[2] GRZESIK W., 2018, Media-Assisted Machining Processes, Mechanik, 91/12, 1050-1056, https://doi.org /10.17814/mechanik.2018.12.186.

[3] KULKARNI H.B., NADAKATTI M.M., PATIL M.S., KULKARNI R.M., 2017, A Review on Nanofluids for Machining, Current Nanoscience, 13/6, 634-653, https://doi.org/10.2174/1573413713666170623094121.

[4] SIDIK N., SAMION S., GHADERIAN J., YAZID M., 2017, Recent Progress on the Application of Nanofluids in Minimum Quantity Lubrication Machining, A Review, Int. Journal of Heat and Mass Transfer, 108, 79-89. https://doi.org/10.1016/j.ijheatmasstransfer.2016.11.105.

[5] SHOKOOHI Y., SHEKARIAN E., 2016, Application of Nanofluids in Machining Processes- a Review, J. Nanoscience and Technology, 2, 59-63.

[6] KHANDEKAR S., SANKAR M., RAMKUMAR J., 2012, Nano-Cutting Fluid for Enhancement of Metal Cutting Performance, Materials and Manufacturing Processes, 27, 1-5. https://doi.org/10.1080/10426914.2011.610078.

[7] GUPTA M., JAMIL M., WANG X., SONG Q., LIU Z., MIA M., et al., 2019, Performance Evaluation of Vegetable Oil-Based Nano-Cutting Fluids in Environmentally Friendly Machining of Inconel-800 Alloy, Materials, 12, 2702, https://doi.org/10.3390/ma12172792.

[8] YOO D.H., HONG K.S., YANG H.S., 2007, Study of Thermal Conductivity of Nanofluids for the application of Heat Transfer Fluids, Thermochim. Acta, 455/1-2, 66-69, https://doi: 10.1016/j.tca.2006.12.006.

[9] SAMUEL J., RAFIEE J., DHIMAN P., YU Z., KORATKAR N., 2011, Graphene Colloidal Suspensions as High Performance Demi-Synthetic Metal-Working Fluids, J. Physical Chemistry, 115, 3410-3415, https://doi.org /10.1021/jp110885n.

[10] HEGAB H., KISHAWY H.A., UMER U., MOHANY A., 2019, A Model for Machining with Nano-Additives Based Minimum Quantity Lubrication, Int. J. Advanced Manufacturing Technology, 102, 2013-2028, https://doi.org/ 10.1007/s00170-019-03294-0.

[11] HEGAB H., UMER U., ESAWI A., KISHAWY H.A., 2020, Tribological Mechanisms of Nano-Cutting Fluid Minimum Quantity Lubrication: A Comparative Performance Analysis Model, Int. J. Advanced Manufacturing Technology, 108, 2, 3133-3139, https://doi.org/10.1007/s00170-020-05450-3.

[12] GHAEDNIA H., JACKSON R., 2013, The Effect of Nanoparticles on the Real Area of Contact, Friction and Wear, ASME, Journal of Tribology, 135/4, 041603, https://doi.org/10.1115/1.4024297.

[13] HEGAB H, DARRAS B., KISHAWY H.A., 2018, Sustainability Assessment of Machining with Nano-Cutting Fluids, Procedia Manufacturing, 26, 245-254, https://doi.org/10.1016/j.promfg.2018.07.033.

[14] NAM J.S., LEE P.H., LEE S.W., 2011, Experimental Characterization of Micro-Drilling Process Using Nanofluid Minimum Quantity Lubrication, Int. J. Mach. Tools Manuf., 51, 649-652, https://doi.org/10.1016/j.ij machtools.2011.04.005.

[15] LI M., YU T., ZHANG R., YANG L., LI H., WANG W., 2018, MQL Milling of TC4 Alloy by Dispersing Graphene into Vegetable Oil-Based Cutting Fluid, Int. J. Advanced Manufacturing Technology, 99, 1735-1753, https://doi.org /10.1007/s00170-018-2576-7.

[16] GRZESIK W., 2017, Advanced Machining Processes of Metallic Materials, Amsterdam, Elsevier. 
[17] GÜNAN F., KIVAK T., YILDRIM C., SARIKAYA M., 2020, Performance Evaluation of $M Q L$ with $\mathrm{Al}_{2} \mathrm{O}_{3} \mathrm{Mixed}$ Nanofluids Prepared at Different Concentrations in Milling of Hastelloy C276 Alloy, J. Materials Research and Technology, 9/5, 10386-10400, https://doi.org/10.1016/j.jmrt.2020.07.018.

[18] KADIRGAMA K., 2020, Nanofluid As an Alternative Coolant in Machining: A Review, J. Advanced Research in Fluid Mechanics and Thermal Sciences, 69, 163-173, https://doi.org/10.37934/arfmts.69.1.163173.

[19] MINH D.T., THE L.T., BAO N.T., 2017, Performance of $\mathrm{Al}_{2} \mathrm{O}_{3}$ Nanofluids in Minimum Quantity Lubrication in Hard Milling of 60Si2Mn Steel Using Cemented Carbide Tools, Advances in Mechanical Engineering, 9/7, 1-9, https://doi.org/10.1177/1687814017710618.

[20] MARGUES A., NARALA S.K., MACHADO A.R. GUNDA R.K., 2015, Performance Assessment of MQSL: Minimum Quantity Solid Lubricant During Turning of Inconel 718, Proc. Inst. Mech. Eng. Part B, J. Engineering Manufacture, 229, 1-16, https://doi.org/10.1177/0954405415592128.

[21] LEE P.H., NAM J.S., LI C., LEE S.W., 2012, An Experimental Study on Micro-Grinding Process with Nanofluid Minimum Quantity Lubrication (MQL), Int. J. Precision Eng. Manuf., 13, 331-338, https://doi.org/10.1007/ S12541012-0042-2. 